\title{
Before and After: English Language Acquisition in Saudi Arabia and the New Possibilities in Teaching and Learning That the COVID-19 Pandemic May Have Brought
}

\author{
Badriah M. Alkhannani \\ English Department, University of Hail, Hail, Saudi Arabia
}

\begin{abstract}
This article examines how the teaching and learning of English as a Foreign Language in Saudi Arabia has evolved over time and the new possibilities the COVID-19 pandemic has brought to teaching and learning of English in Saudi Arabia. Various factors have influenced the pace and degree to which the English language has propagated in Saudi Arabia ever since it was first introduced. Learners of English also continue to be affected by several inherent and external factors when learning the English language. On top of having to grapple with first language and culture interferences, learners of English in Saudi Arabia have also to navigate unfavorable learning environments, lack of experiential exposure to English, and foreign language anxiety. Although the COVID-19 pandemic may have seemingly created issues (e.g., a reduction in time for interaction with peers and teachers) for learners of English due to emergency remote teaching, it has opened up new possibilities that can be the subject of additional research and development. The benefits of online learning, translingual practices, and collaborative teaching should be further explored to benefit from the new normal of mandatory online learning that has arisen due to the pandemic.
\end{abstract}

Index Terms-English language, Saudi Arabia, teaching, learning, COVID-19 pandemic, English education

\section{INTRODUCTION}

Educational expenditure has been a priority for the Saudi Arabian government and in particular, investment into developing and propagating English as a foreign language. Most recently, the Tatweer project was implemented to look into the enhancement of the English language skills of Saudi Arabian students (Assulaimani, 2019). The use of technology and online learning appears to be the common theme underpinning the nine phases of the Tatweer project. Despite the substantial investment and effort into developing English as a foreign language, the reasons as to the lackluster performance of an average educated Saudi Arabian user of English has been the subject of much research. The COVID-19 pandemic adds another unknown dimension to the acquisition of English as a foreign language in Saudi Arabia. As such, to fully appreciate the nuances that influence the considerations with regard to online learning in a post-COVID-19 world, it is vital to trace the history and issues which have plagued the acquisition of English in Saudi Arabia.

\section{LITERATURE REVIEW}

\section{A. English as a Foreign Language in Saudi Arabia}

English as a foreign language in Saudi Arabia has been shaped by various factors and events since it was introduced into Saudi Arabia. Culture, community, religion, and learners' primary language - Arabic, can be seen to be the more prominent factors that have influenced and would continue to influence the development of the learning and teaching of English as a foreign language (Alrabai, 2018). These factors have in general led to a resistance to the English language (Elyas \& Picard, 2010). Despite the initial resistance to English when it was first introduced to accelerate Saudi Arabia's integration into the world (Faruk, 2013), several key events have, over the years, hastened the development and investment in English as a foreign language in Saudi Arabia (Alshahrani, 2016).

Although it is not exactly clear when English as a foreign language was initially introduced in Saudi Arabia, it was first introduced into the Saudi Arabia educational system via the elementary school system four times a week (45 minutes a session) in 1937. In 1942, as part of the restructuring of the Ministry of Education, the introduction of English was removed from elementary schools and reintroduced at intermediate and secondary school levels at the previous frequency. Subsequently, in 1974, this was increased to six 45 minutes sessions a week but reverted to four 45 minutes sessions a week in 1980 (Al-Hajailan, 2006). The reasons for reducing the contact hours of English as a foreign language in the public education system in 1974 were not explicitly clear but it could be a response to the natural resistance to learning other languages like English (Barnawi \& Al-Hawsawi, 2017). 
Running parallel to the formal introduction of English as a foreign language, the discovery of oil in the 1930s, globalization of English (Sharifian, 2009), acceleration of Saudi Arabia's integration with the world, post-September 11 political and social pressures, the 'Arab Spring', the 2008 Global Financial Crisis, the birth of the Islamic State of Iraq and Syria, tumbling oil prices have impacted English education policy reforms in Saudi Arabia (Phan \& Osman, 2015).

The next significant phase of English as a foreign language in Saudi Arabia commenced in 2005 when the thengovernment realized the need to reduce its dependence on revenue from the oil industry and to create a modern allrounded economy comparable to developed countries (Barnawi \& Al-Hawsawi, 2017). A visible outcome of the shift in economic policy is the increase in the number of universities from 8 in 2001 to 36 in 2015 (Alshahrani, 2016). With all universities having an English Department and English as a foreign language being taught at least one semester during an undergraduate's education, the proportion of people learning English at a tertiary level could have increased at a conservative rate corresponding to the rate of increase in the number of universities from 2001 to 2015.

Subsequent to the shift in economic policy, and, notwithstanding the longstanding issues in English language acquisition, English has been elevated to the medium of instruction in technical education, medicine, and many other majors (Alhaisoni \& Arabia, 2013). From a practical perspective, the status of being the only foreign language taught in Saudi Arabian public and private educational institutions has also led learners of English to recognize the importance and significance of English in business, trade, and higher education (Al-Seghayer, 2014). Building on its progress, the Saudi Arabian government continues to invest heavily in the acquisition of English as a foreign language in Saudi Arabia (Barnawi \& Al-Hawsawi, 2017) This can be seen via investment in the recruitment of English teachers, the establishment of language labs, continual development, and improvement of the English curriculum, and formalized teacher training (Alhaisoni \& Arabia, 2013).

\section{B. Key Challenges In English Language Teaching and Acquisition}

Despite the steady progression and propagation of English as a foreign language in Saudi Arabia as a whole, learners and teachers of English face multiple challenges in the acquisition and teaching of English (Al-Nasser, 2015). In particular, Saudi Arabian learners of English face challenges in speaking and writing. This is reflected in the observation that despite English being introduced into the educational system relatively early, most Saudi students graduate from high school with limited English skills (Alrabai, 2014). In this regard, understanding these challenges and the way English as a foreign language in Saudi Arabia has progressed could help lay the foundation for the conceptualization of potential solutions or policies in relation to the continual propagation of English as a foreign language in Saudi Arabia going forward.

1. First language interference

The first language of learners of the English language in Saudi Arabia - Arabic (Indo-European language family), is from a very different language group from English (Afroasiatic language family) (Dajani et al, 2013). As such, the resulting differences in sounds of Arabic alphabets from English alphabets, verb system, syntax, sentence structure, vowel and consonant sounds, word stress, sound elision, grammar, and vowel quality and length (Rababah, 2005), are likely to cause Saudi Arabian students' difficulties at an early stage of learning the English language (Alasmari et al, 2016).

\section{Cultural influences}

With Saudi Arabia's official religion being Islam and its constitution based on the Holy Quran (which is written in Arabic), it would not come as surprise to many that English (and the acquisition of the English language) is not often seen as a "neutral language" (Mahboob \& Elyas, 2014). Saudi culture is a key language domain that shapes foreign language acquisition in Saudi Arabia (Alrabai, 2018). Saudi culture is closely intertwined with the Saudi community and can be defined as a collective and religious tribal community that places a lot of emphasis on traditions, alliances, and family (Alrahaili, 2014). In this regard, the Saudi community has often misconstrued that learning English may affect the learning of Arabic or the dilution of Saudi culture (Al-Nasser, 2015). This has led to parents' holding an unfavorable view toward the acquisition of English, which may lead to demotivation among students learning English (Barnawi \& Al-Hawsawi, 2017).

3. Unfavorable teaching and learning practices

Adding to inherent complexities and difficulties in the acquisition of English, Saudi Arabian students learning the English language are often taught English using their first language - Arabic (Alhawsawi, 2013) (Rababah, 2005), In this context, Arabic is used to teach English grammar, explain difficult vocabulary or to clarify complex concepts. Coupled with the dominant role of the teacher in the Saudi English classroom (where the focus is mainly on getting students to pass exams), students resort to ineffective learning techniques such as rote learning and memorization without understanding (Al Rashidi \& Phan, 2015). Active steps such as praise of students, providing relatable real-life examples when teaching, being slow to correct the mistakes of students and constant encouragement are also noted to be a contributing factor in the poor learning environment for Saudi English learners (Al Rashidi \& Phan, 2015). As a result, when viewed in totality, these teaching practices would naturally reduce the students' exposure to English, affect their view on the importance of the language they are learning, deprive them of opportunities to communicate and practice English in an authentic situation and create a dependence on Arabic in the learning of English (Alrabai, 2018).

4. Lack of experiential exposure to English 
Learners of English in Saudi Arabia are likely to find that they have limited opportunities to practice and immerse themselves in the language other than when in a classroom setting (Khan, 2011). This lack of opportunity to finetune and practice the English language can be attributed to Arabic being Saudi Arabia's official language and frequently the main language for communication in the country (Alrabai, 2018). Furthermore, as Arabic is highly regarded by parents due to its status as the official and national language, they are more likely to communicate with their children only in Arabic (Alsairi, 2018), leaving English language learners mainly with opportunities to use the language in classrooms. This limited use is further curtailed when English teachers dominate the classroom with a lot of speaking and leaving students with little opportunity to speak or to ask questions (Alkubaidi, 2014). To the extent that students can be exposed to even a fraction of what they are exposed to in Arabic, there should be improvements in their standard of English (Jamali, 1991).

5. Foreign language anxiety

Foreign language anxiety is situation-specific anxiety that is experienced during the acquisition of a foreign language in classroom learning (Horwitz et al, 1986) (Horwitz et al, 1991). In general, it negatively affects foreign language performance and can be viewed as one of the more significant factors that affect foreign language acquisition (Jamilah, 2017). A study conducted to examine the correlation between foreign language anxiety and language performance found that the most common causes of anxiety include giving oral presentations, performing in front of classmates, and interacting with native speakers (Woodrow, 2006). Language distance between the learner's first language (i.e., Arabic in Saudi Arabia) and the language acquired (English) has also been identified as having a positive correlation to foreign language anxiety (Zhang, 2019). To the extent that foreign language anxiety is reduced during lessons, students can be better engaged and should correspondingly lead to a more positive learning outcome (Elkhafaifi, 2005).

\section{Covid-19 Pandemic and the Acquisition of English in Saudi Arabia}

\section{COVID-19 and emergency remote teaching}

The pace and extent to which the COVID-19 pandemic took the world by storm, altering many aspects of all our lives, would remain a shared history for the population of the world that has lived through the days. Ways of teaching and learning that were traditionally known at various academic levels have been fundamentally altered. School closures and emergency remote teaching, where possible, were also implemented at an unprecedented scale (Yi \& Jang, 2020) (Hodges et al, 2020). Materials that were traditionally used in the classroom had to be altered, repurposed, and redesigned for online use, Learning Management Systems replaced classroom learning, and, instructors and students alike had to reconfigure their homes to suit online teaching and learning (Sayer \& Braun, 2020). Not to be viewed in the same light as online teaching, blended learning, or flipped classrooms, "emergency remote teaching" is a temporary, sudden, and unplanned shift of instructional delivery to a remote delivery mode (Hodges et al, 2020). Like their counterparts globally, the Saudi Arabia Ministry of Education announced a switch to online classes within days to ensure a safe and secure process for learning (Khalil et al, 2020). Notwithstanding that Saudi Arabia has taken a progressive view regarding online learning (e.g. the National Plan for Information Technology) (Asmari, 2012) (AlHamidi, 2013), it may be an opportune time to consider the issues of online learning of English in Saudi Arabia as the path to the end of the pandemic is not particularly clear at this point in time.

2. The use of translingual practices and pedagogy for online learning

Translingual practice is broadly defined as a hybrid, impromptu, evolving, and spontaneous language practice that seeks to bridge the gap between languages and the creative use and reorganization of pre-existing knowledge for communication and self-representation (Canagarajah, 2013) (Horner et al, 2011). The translingual theory contests monolingualism where there should be a separation of languages and that languages should maintain their existing structures and form even in contact (Canagarajah, 2013) (Kato \& Kumagai, 2020). While monolingualism grants authority to native speakers of the language, whilst viewing non-native speakers as incompetent users of the language, translingualism effectively empowers learners of the language as creative users and not a borrower of the language (Creese \& Blackledge, 2010). In recent research, researchers observed emergency remote learning classes and noted that where both teachers and students adopt translingual practices online, students did not appear to view language differences as a problem (Yi \& Jang, 2020). Instead, as they embraced the differences, attempted to overcome, resolve and navigate these differences.

In the Saudi Arabian context, the translingual pedagogy should be considered and explored as a potential solution to first language interference, foreign language anxiety, and unfavorable learning and teaching practices faced by learners of English. It would also be worthwhile to note that whilst the translingual pedagogy in the Saudi Arabian context involves free interaction and use of Arabic and English in the English language classroom, it should be viewed as different from the unfavorable teaching practice of an authoritative English language teacher teaching English grammar in Arabic noted earlier in this paper. As much of current research around translingual practice is not specific to Saudi Arabia, further research should be carried out to assess how translingual practice can be effectively implemented in Saudi Arabian educational institutions to aid in the learning of English.

3. Online learning as a student-centered practice in Saudi Arabia

The pedagogical benefits of online learning have been the subject of much research and analysis in recent years. However, in the unique context of Saudi Arabia, the practical benefits of online learning for Saudi Arabian learners of English - students being able to study at their own pace (Farooq \& Javid, 2012), and the convenience of online learning 
due to the reduction of travel time (Alasmari et al, 2016). Also, the way learning results in a more enriching experience for intrinsically motivated and initiated students (Al-Qahtani \& Higgins, 2013), all of which must factor in the consideration for online learning in the post-COVID-19 world. Detailed research could be considered to understand the extent of non-pedagogical benefits of online learning of English for Saudi Arabian students.

4. Potential reduction of time for students to interact with peers in English

As noted earlier in the paper, a potential difficulty faced by English language learners in Saudi Arabia is the lack of exposure and usage of English. Switching to online learning would mean that the rich English language interaction between teacher and students and between classmates would be significantly reduced as students would not be able to engage in an informal small group discussion with peers (Sayer \& Braun, 2020) or have impromptu personal discussions with the teacher. That being said, it may be worthwhile to consider if the opportunity to learn English through the natural interaction between peers truly exists to a large extent in a Saudi Arabian English classroom. This is because, where the English teacher usually dominates the classroom, and students are seldom provided with the opportunity to speak up in English, there may be a lack of motivation to use or apply the English language in an informal situation (Khan, 2011). Should further research or observation be able to demonstrate that Saudi Arabian learners of English do not extensively engage in English language interaction in the physical classroom, a reduction of time for students to interact with peers in English in an online classroom should not be expected to be observed?

5. Lack of digital competence among English language teachers

Digital competence can be broadly defined as having the knowledge and ability in relation to current information and communication technology and the capability to manage the latest technology and digital information (Ferrari \& DIGCOMP, 2013). It is also associated with three integrated competencies: technology proficiency, pedagogical compatibility, and social awareness (Zhao et al, 2002). It is clear from various literature that the digital competence of teachers has been of increasing importance before the COVID-19 pandemic due to how teachers' interaction with digital resources may potentially shape pedagogy, interaction, and communication with students (Burden et al, 2016). As such, information and communication technology should be considered an important skill for foreign language teachers in addition to linguistic abilities (Abdulteef \& Al Khateeb, 2017). Emergency remote teaching because of the pandemic further highlights the rapid digital transformation that is taking place and the importance of digital competence among English language teachers. However, from a Saudi Arabian perspective, it is noted in an exploratory study of English language teachers in Saudi Arabia that the majority of teachers are not adequately digitally competent according to the level and standards required to enable them to be good digital teachers of the twenty-first century (Abdulteeef \& Al Khateeb, 2017). These results are likely attributable to inexperience, lack of proper training and prior knowledge in information communication technology, or poor performing unmotivated individuals (Maderick et al, 2016). As such, given the urgency of this issue as online learning of English in Saudi Arabia is likely to be more widely accepted and taken up, the research could be conducted to understand how teachers can be motivated to bridge the digital gap. Where the digital divide among English language teachers is narrowed (i.e., digital competence achieved), it is envisaged that the positive effects can be benefited by their students (Ala-Mutka, 2011). In the meantime, support should be given to teachers who have accessed themselves to be less competent digitally and encouraged to take up courses to improve their digital capabilities.

6. Collaborative teaching for online learning

Collaborative teaching has been, to a certain degree, the subject of research over time. It has been defined as " any academic experience in which two professors work together in designing and teaching a course that itself uses group learning techniques" (Robinson \& Schaible, 1995) or "two or more people sharing responsibility for educating some or all of the students in a classroom" (Villa et al, 2008). In light of the COVID-10 pandemic, where cross-border travel is largely curtailed, the possibility of collaborative teaching online with native English-speaking and non-native Englishspeaking teachers can be explored. In the context of the Saudi Arabian English classroom, a collaborative teaching arrangement for online learning could be envisaged as a pedagogy that may potentially mitigate the difficulties (e.g., cultural interferences, unfavorable teaching practices, and a lack of experiential English learning environment) encountered by an English language learner in Saudi Arabia. Recent small-scale research has shown that teachers with differing cultures and backgrounds when working together in an online English classroom have been able to provide a much more engaging and enriching teaching environment for students (Yi \& Jang, 2020). All that being said, there are issues like conflict and non-genuine collaboration with regard to collaborative teaching (Carless \& Walker, 2006) (Nevin et al, 2009) that should be mitigated to ensure that these do not diminish the benefits of collaborative teaching. Furthermore, before large-scale collaborative teaching is implemented in Saudi Arabia, research should be conducted to understand the true benefits of collaborative teaching online in the Saudi Arabian context and feasibility studies should also be conducted to identify any practical or technical difficulties during implementation.

7. Academic performance

A recent study on how academic performance has been affected by emergency remote teaching due to the pandemic showed that overall, students have achieved better academic results under emergency remote teaching (Iglesias-Pradas et al, 2021). The results from the study also suggest that: “distal factors -higher education instructors' knowledge, skills, and attitudes toward technology; their qualification; and institutional, organizational, and administrative factors, together with instructors' and students' equipment and digital skills- do have an effect on student outcomes". As much 
as the results of the study may provide justification for further implementation of online learning of English in Saudi Arabia, further research in relation to Saudi Arabia should be carried out to understand how academic performance has been affected due to online learning. In particular, to understand if online learning does result in a better outcome for the learning of English in Saudi Arabia, a holistic assessment method that could accurately measure language competencies before and after online learning was implemented would be required.

\section{CONCLUSION}

The issues explored for teaching the English language as a foreign language in a post-COVID-19 world are largely around online teaching. As more research that is specific to Saudi Arabia is conducted in this regard, these issues should be refreshed, recalibrated, and examined in line with the goals and implementation details of the Tatweer project. This would ensure that best practices and correspondingly the best outcomes for English as a foreign language in Saudi Arabia could be achieved going forward.

\section{REFERENCES}

[1] Ahmed Abdulteeef M. Al Khateeb. (2017). Measuring Digital Competence and ICT Literacy: An Exploratory Study of InService English Language Teachers in the Context of Saudi Arabia. International education studies, 2017, Volume 10, Issue 12, Page 37-48.

[2] Alhaisoni, E., \& Arabia, S. (2013). Teaching English In Saudi Arabia: Prospects AND Challenges. Academic Research International, 2013, Volume 4, Issue 1, Page 112-118.

[3] Al Hajailan, D. T. (2003). Teaching English in Saudi Arabia. Edition 1424- 2003. Riyadh: Aldar Al sawlatiah.

[4] Al-Hamidi, M. (2013, November 13). Teaching English in Saudi Arabia from paper into E-learning. Asharq Al-Awsat. Retrieved from http://aawsat.com/home/article/8730.

[5] Alhawsawi, S. (2013). Investigating student experiences of learning English as a Foreign Language in a preparatory programme in a Saudi university, doctoral thesis, University of Sussex, Brighton, UK.

[6] Alkubaidi, M. A. (2014). The relationship between Saudi English major university students' writing performance and their learning style and strategy use. English Language Teaching, 7(4), 83-95.

[7] Ala-Mutka, K. (2011). Mapping digital competence: Towards a conceptual understanding. Sevilla: Institute for Prospective Technological Studies. European Commission-Joint Research Centre.

[8] Al-Nasser, A (2015). Problems of English Language Acquisition in Saudi Arabia: An Exploratory-cum-remedial Study. Theory and Practice in Language Studies (Vol. 5, Issue 8, Page 1612-1619).

[9] Alrabai, F. (2014). Motivational practices in English as a foreign language classes in Saudi Arabia: Teachers' beliefs and learners perceptions. Arab World English Journal, Volume.5, Issue 1, Page 224-246.

[10] Alrabai, F. (2018). Learning English in Saudi Arabia. 10.4324/9781315688466-5.

[11] Alrahaili, M (2014). Predictors of L2 attitudes and motivational intensity: a cross-sectional study in the Saudi EFL context, doctoral thesis, the University of Newcastle, Australia.

[12] Al Rashidi, O., \& Phan, H. (2015). Education context and English teaching and learning in the Kingdom of Saudi Arabia: an overview. English for Specific Purposes World, 8(5), 33-44.

[13] Alsairi, M. (2018). Earlier Is Better: Learning English in Saudi Arabia. English Language Teaching, v11 n1 p141-149.

[14] Al-Asmari AR. (2012). Evaluating the Prospects of Integrating Technology in Pre-service EFL Teacher Training. Arab World English Journal. 2011;2(2):133-166.

[15] Al-Asmari, A.M. and Khan, M.S.R. (2014), "E-Learning in Saudi Arabia: past, present and future", Near and Middle Eastern Journal of Research in Education, Volume 2014, Issue 1, Page 1-11.

[16] Al-Qahtani AAY, Higgins SE. (2013). Effects of traditional, blended and e-learning on students achievement in higher education. Journal of Computer Assisted Learning. 2013;29(3):220-234.

[17] Al-Saraj, TM. (2014). 'Foreign language anxiety in female Arabs learning English: case studies', Innovation in Language Learning and Teaching, vol. 8, no. 3, pp. 257-278, doi: 10.1080/17501229.2013.837911.

[18] Al-Seghayer, K. (2014). The four most common constraints affecting English teaching in Saudi Arabia. International Journal of English Linguistics, 4(5), 17-26.

[19] Assulaimani, T. (2019). The Future of Teaching English in Saudi Arabia. Universal Journal of Educational Research 7(8): 1623-1634.

[20] Barnawi O.Z., \& Al-Hawsawi S. (2017). English Education Policy in Saudi Arabia: English Language Education Policy in the Kingdom of Saudi Arabia: Current Trends, Issues and Challenges. In: Kirkpatrick R. (eds) English Language Education Policy in the Middle East and North Africa. Language Policy, vol 13. Springer, Cham, 10.1007/978-3-319-46778-8_12.

[21] Burden, K., P. Aubusson, S. Brindley, and S. Schuck. (2016). "Changing Knowledge, Changing Technology: Implications for Teacher Education Futures.” Journal of Education for Teaching 42 (1), 1-13.

[22] Carless, D., \& Walker, E. (2006). Effective team teaching between local and native-speaking English teachers. Language and Education, 20, 463-477.

[23] Canagarajah, A. S. (2013). Literacy as translingual practice: Between communities and classrooms. New York, NY: Routledge.

[24] Creese, A., and A. Blackledge. (2010). "Translanguaging in the Bilingual Classroom: A Pedagogy for Learning and Teaching?" The Modern Language Journal 94 (1), 103-115.

[25] Dajani, Basma \& Omari, Fatima. (2013). A Comparison Between the Arabic and the English Language. Procedia - Social and Behavioral Sciences.

[26] Elkhafaifi, H. (2005). Listening comprehension and anxiety in the Arabic language classroom. National Federation of Modern Language Teachers Associations, 89(2), 206-220. 
[27] Elyas, T., \& Picard, M. (2010). Saudi Arabian educational history: Impacts on English language teaching. Education, Business and Society: Contemporary Middle Eastern Issues, 3(2), 136 -145.

[28] Faruk, S. (2013). English language teaching in Saudi Arabia: A world system perspective. Scientific Bulletin of the Politehnica University of Timişoara Transactions on Modern Languages, 12(1-2), 73-80.

[29] Farooq U, Javid C. (2012). Impact of e-learning on English Language Learning at Undergraduate Level at Taif University (KSA). Edulearn12 Proceedings. 2012;6961-6969.

[30] Farzad Sharifian. (2009). English as an International Language: Perspectives and Pedagogical Issues, $3^{\text {rd }}$ Edition, Multilingual Matters.

[31] Ferrari, A., DIGCOMP: A Framework for Developing and Understanding Digital Competence in Europe. , EUR 26035, Publications Office of the European Union, Luxembourg, 2013, ISBN 978-92-79-31465-0, doi:10.2788/52966, JRC83167.

[32] Habbash, M. (2011). Status change of English and its role in shaping public education language policy and practice in Saudi Arabia: A postmodernist critical perspective. Unpublished Doctoral Dissertation, University of Exeter, Exeter.

[33] Halliday, M., A. McIntosh and P. Strevens. (1972/1984) (8th impression) 'Learning Foreign Languages. In R. Nasr (ed.), Teaching and Learning English. Harlow: Longman.

[34] Hodges, C., Moore, S., Lockee, B., Trust, T., \& Bond, A. (2020). The difference between emergency remote teaching and online learning. EDUCAUSE Review.

[35] Horner, B., Lu, M. Z., Royster, J. J., \& Trimbur, J. (2011). Language difference in writing: Toward a translingual approach. College English, 73(3), 303-321.

[36] Horwitz, E. K., M. B. Horwitz, and J. Cope. (1986). "Foreign Language Classroom Anxiety.” The Modern Language Journal $70(2): 125-132$.

[37] Horwitz, E. K., M. B. Horwitz, and J. A. Cope. (1991). "Foreign Language Classroom Anxiety." In Language Anxiety: From Theory and Research to Classroom Implications, edited by E. K. Horwitz and D. J. Young, 27-39. Englewood Cliffs.

[38] Iglesias-Pradas S., Hern'andez-García A., Chaparro-Pel'aez J. and Luis Prieto J. (2021). Emergency remote teaching and students' academic performance in higher education during the COVID-19 pandemic: A case study. Computers in Human Behavior 119, 106713.

[39] Jamali, I. (1991). Language Exposure and Second Language Learning. The English Teacher. Vol, 20. Pp., 20-31.

[40] Jamilah, S. (2017). Anxiety in English Language Learning: A Case Study of English Language Learners in Saudi Arabia, Canadian Center of Science and Education. Vol. 10, No. 7, 1-7. 10.5539/elt.v10n7p1.

[41] Alasmari, J, Watson, J and Atwell, ES. (2016). A comparative analysis between Arabic and English of the verbal system using google translate. In: Proceedings of IMAN'2016 4th International Conference on Islamic Applications in Computer Science and Technologies. IMAN'2016 4th International Conference on Islamic Applications in Computer Science and Technologies, 20-22 Dec 2016, Khartoum, Sudan.

[42] Reiko Kato \& Yuri Kumagai. (2020). Translingual practices in a 'Monolingual' society: discourses, learners' subjectivities and language choices, International Journal of Bilingual Education and Bilingualism, DOI: 10.1080/13670050.2020.1799318.

[43] Khalil, R., Mansour, A.E., Fadda, W.A. et al. (2020). The sudden transition to synchronized online learning during the COVID19 pandemic in Saudi Arabia: a qualitative study exploring medical students' perspectives. BMC Med Educ 20, 285.

[44] Khan, I. (2011). Learning difficulties in English: Diagnosis and pedagogy in Saudi Arabia. Educational Research, 2(7), 12481257.

[45] Maderick, J. A., Zhang, S., Hartley, K., \& Marchand, G. (2016). Preservice teachers and self-assessing digital competence. Journal of Educational Computing Research, 54(3), 326-351.

[46] Mahboob, A \& Elyas, T. (2014). 'English in the Kingdom of Saudi Arabia', World Englishes, vol. 33, no. 1, pp. 128-142, doi: 10.1111/weng. 12073.

[47] Merzin Alshahrani. (2016). A Brief Historical Perspective of English in Saudi Arabia. Journal of Literature, Languages and Linguistics: Vol.26, Issue 2, 2016, 43-47.

[48] Nevin A., Thousand J. and Villa R. (2009). Collaborative teaching for teacher educators - What does the research say? Teaching and Teacher Education 25; 569-574.

[49] Phan Le Ha \& Osman Z. Barnawi. (2015). Where English, neoliberalism, desire and internationalization are alive and kicking: higher education in Saudi Arabia today, Language and Education, 29:6, 545-565, DOI: 10.1080/09500782.2015.1059436.

[50] Rababah, G. (2005). Communication problems facing Arab learners of English: general problems of Arab learners of English. Journal of Language and Learning, 3(1), 180-197

[51] Robinson, R., \& Schaible, R. (1995). Collaborative teaching: reaping the benefits. College Teaching, 43(2), 57-60.

[52] Sayer, P, Braun, D. (2020). The disparate impact of COVID-19 remote learning on English learners in the United States. TESOL Journal. 2020; Volume11, Issue3, e00546. https://doi.org/10.1002/tesj.546.

[53] Villa, R., Thousand, J., \& Nevin, A. (2008). A guide to co-teaching: Practical tips for facilitating student learning (2nd ed.). Thousand Oaks, CA: Corwin Press.

[54] Woodrow, L. (2006). Anxiety and speaking English as a second language. RELC Journal, 37(3), 308-328.

[55] Yi, Y, Jang, J. (2020). Envisioning possibilities amid the COVID-19 pandemic: Implications from English language teaching in South Korea. TESOL Journal. 2020; Volume11, Issue3, e00543. https://doi.org/10.1002/tesj.543.

[56] Zhang, X. (2019). Foreign Language Anxiety and Foreign Language Performance: A Meta-Analysis. The Modern Language Journal, 103: 763-781.

[57] Zhao, Y., Pugh, K., Sheldon, S., \& Byers, J. L. (2002). Conditions for classroom technology innovations. Teachers' college record, 104(3), 482-515.

Badriah M. Alkhannani from Ha'il in Saudi Arabia, Assistant Professor at Teaching English language Hail university, hail Vice President of Female Campus at Hail University, her research interests are teaching English language Gifted English language learners English language in Saudi context. 